\title{
La Raison exaltée. Études sur "De la Littérature" de Madame de Staël, sous la direction de Marc André Bernier
}

\section{Stéphanie Genand}

\section{(2) OpenEdition}

1 Journals

\section{Édition électronique}

URL : http://journals.openedition.org/studifrancesi/3777

DOI : 10.4000/studifrancesi.3777

ISSN : 2421-5856

Éditeur

Rosenberg \& Sellier

\section{Édition imprimée}

Date de publication : 1 décembre 2012

Pagination : 583-584

ISSN : 0039-2944

\section{Référence électronique}

Stéphanie Genand, «La Raison exaltée. Études sur "De la Littérature" de Madame de Staël, sous la direction de Marc André Bernier », Studi Francesi [En ligne], 168 (LVI | III) | 2012, mis en ligne le 30 novembre 2015, consulté le 05 mars 2021. URL : http://journals.openedition.org/studifrancesi/3777 ; DOI : https://doi.org/10.4000/studifrancesi.3777

Ce document a été généré automatiquement le 5 mars 2021.

\section{cc) (1)}

Studi Francesi è distribuita con Licenza Creative Commons Attribuzione - Non commerciale - Non opere derivate 4.0 Internazionale. 


\title{
La Raison exaltée. Études sur "De la Littérature" de Madame de Staël, sous la direction de Marc André Bernier
}

\author{
Stéphanie Genand
}

\section{RÉFÉRENCE}

AA. VV., La Raison exaltée. Études sur "De la Littérature" de Madame de Staël, sous la direction de Marc André BERNIER, Laval, P.U.L., 2011, pp. 142.

Si l'ouvrage dirigé par Marc André Bernier s'inscrit dans l'actuel renouvellement des études staëliennes (voir notamment K. Szmurlo, G. de Staël: forging a politics of mediation, A. Craiutu, A Virtue for courageous minds: Moderation in French political Thought (1748-1830) et B. Binoche (Religion privée, opinion publique), le choix d'étudier De la Littérature lui confère une importance singulière. Le traité de 1800, malgré la «querelle de la perfectibilité» qui transforme son audace théorique en succès de scandale, a rarement fait l'objet d'études monographiques. Éclairé et commenté grâce à deux excellentes éditions critiques (G. Gengembre et J.Goldzink, Garnier-Flammarion, 1991 et A. Blaeschke, Garnier, 1998, dont le travail précieux nourrit la réédition dans les $F u v r e s$ complètes, série 1, t. 2, Champion, à paraître en novembre 2012), il reste paradoxalement à l'écart des récentes analyses qui valorisent la pensée politique de G. de Staël. Fondée sur un corpus explicitement théorique - Des Circonstances actuelles et les Considérations sur la Révolution française - cette lecture intègre avec difficulté un texte pourtant voué par son titre à la problématique du «rapport» entre la littérature et «les institutions sociales». Traité affranchi de toute "poétique», histoire des civilisations et des modèles culturels où surgit la voix d'une femme qui revendique le droit de «mêler ainsi les affections de [s]on âme aux idées générales» (éd. A. Blaeschke, p. 421), De la Littérature impose une hétérogénéité qui déjoue les paradigmes classiques. La sensibilité, sous la plume d'un «je» qui enchevêtre la réflexion et le récit mélancolique d'une jeunesse disparue - «Ah! Qu'on était heureux il y a dix années...» (p. 420) - compromet la lecture 
univoque et offre aux détracteurs de la femme théoricienne les armes pour la discréditer. L'ouvrage de Marc André Bernier, loin d'ignorer cette ambiguïté de l'écriture staëlienne, invite à la convertir en atout: si elle a traditionnellement nourri les préjugés biographiques, elle devient l'instrument de la «connaissance de soi» (p. 1) à laquelle aspirent les philosophes progressistes, de Cabanis à Condorcet. Inscrit dans la reconfiguration des sciences de l'homme au tournant des Lumières, De la Littérature dessine les contours d'un nouveau savoir, fondé sur l'alliance de la philosophie et de la sensibilité. «La raison exaltée», formule à valeur de programme que Marc André Bernier emprunte au chapitre consacré à la littérature du Nord, retrace sous l'oxymore l'audace épistémologique et morale de G. de Staël: la sensibilité, qu'elle se décline en enthousiasme, éloquence, féminité ou imagination, garantit seule une connaissance de l'homme devenue indispensable au sortir de la Terreur.

2 Ce projet inspire la structure tripartite de l'ouvrage: qu'il s'agisse de penser la «littérature» moderne, au service de la république et de la réconciliation collective (I), de réfléchir à la place des femmes et aux atouts de leur publicité (II) ou de fonder la création sur l'imagination et le mystère (III), De la Littérature invente un nouveau modèle de rationalité. Qualifié d'«alliance entre l'idée et le sang» (p.4), un tel programme convertit en ressort philosophique le mélange de réflexion et de passion qui traverse l'œuvre staëlienne. Libérée de tout ancrage personnel, elle assigne à la création les contours politiques de la cité et de l'histoire (G. GENGEMBRE et J. GOLDZINK, "De la Littérature", cuvre politique, pp. 13-24), invente une éloquence républicaine où la grandeur s'appuie sur la subjectivité de l'orateur (M. A. BERNIER, Un néocicéronianisme de l'exaltation, pp. 25-34) et cherche, dans le "partage des cultures» (p. 35) qui substitue Condorcet à Buffon, une vérité des sciences morales (M. DELON, Buffon et l'influence de la littérature, pp. 35-43). Défendue par une plume féminine, cette ambition expose Staël aux griefs de la «femme auteur»: A. GOODEN (Dame "comme il faut» ou femme écrivain? "De la Littérature" et l'angoisse de la femme auteur, pp. 47-64) rappelle la douleur et l'échec de ses héroïnes, victimes d'une féminité brisée par la Révolution et à qui De la Littérature tente de donner une place en s'interrogeant sur «les femmes qui cultivent les lettres» (M.-L. GIROU-SWIDERSKI, L'autre Révolution? De la littérature et des femmes, pp. 65-76). Restent à définir les conditions de la création dans ce contexte: la violence révolutionnaire requiert des fictions sensibles, dont il faut trouver le modèle en acceptant l'hypothèse d'une perfectibilité de l'imagination (D. DUMouchel, De la supériorité des Modernes. Quelques réflexions sur les limites de l'imagination et sur la perfectibilité esthétique dans De la Littérature, pp.79-90). La passion, telle qu'elle sera illustrée par Corinne, invite De la Littérature à valoriser l'univers ossianique (C. SETH, La Littérature nordique à l'épreuve du romanesque. Ossian entre "De la Littérature" et "Corinne", pp.91-106). Elle permet enfin de donner un visage à la férocité de l'âme humaine, révélée par la Terreur et que Staël met au jour en libérant «nos démons (re) découverts» (C. DUBEAU, L'Homme féroce: passions, violence et limites de l'invention littéraire dans "De la Littérature", pp. 107-130).

3 La Raison exaltée propose une relecture à la fois solide et stimulante de la pensée staëlienne. Si De la Littérature constitue le corpus de l'ouvrage, l'axe construit par M. A. Bernier invite à situer l'ensemble de cette œuvre dans l'histoire des sciences de l'homme. Cette ambition originale, outre qu'elle affranchit la féminité des lectures malveillantes, souligne la force conciliatrice et l'audace d'une méthode capable d'inventer une connaissance sensible. Quelques contributions restent ponctuellement 
en-deçà des ambitions du volume (c'est le cas, notamment, de celles qui sont consacrées aux femmes). Mais l'ensemble reste des plus convaincants et suggère que l'heure est venue d'entendre l' «autre chose qui guide la plume de l'auteur» (C. Dubeau, p. 128). 